Адрес статьи / To link this article: http://cat.ifmo.ru/ru/2017/v2-i1/114

\title{
Применение элементов теории узлов к автоматизированному проектированию монгольских плетёнок
}

\author{
Т.В. Кочева
}

Институт физического материаловедения СО РАН, Россия

$$
\text { tavako@mail.ru }
$$

\begin{abstract}
Аннотация. У многих народов имеется традиция использования разнообразных узлов в хозяйственных и иных целях. Красивые рисованные узлы издревле применяются для украшения многих предметов, и в наше время широко используются дизайнерами. Почти два столетия тому назад изучением узлов занялись математики, и с тех пор теория узлов успешно развивается, находя применение в разных научных направлениях — физике, биологии, искусстве. В статье описана попытка классификации традиционных монгольских плетёных орнаментов по таблицам простых узлов с целью усовершенствования работы автоматизированного редактора плетёнок MonPlet.
\end{abstract}

Ключевые слова: узел, теория узлов, плетёный узор, автоматизация проектирования, MonPlet.

\section{Введение}

С узлами мы знакомимся в детстве, когда нас учат завязывать шнурки, заплетать косички и делать банты. Мама показывает, как завязать узелок на нитке, а папа — как привязать к леске рыболовный крючок. Так мы понимаем, что узлы незаменимы в хозяйственной деятельности. Там, где используется веревка, нитка, канат, - там с древнейших времён применяются разнообразные узлы и техники плетения. Существует множество китайских узлов, гордиев узел, кельтские узлы, морские узлы... Многие из них не только практичны, но и красивы, и именно они, перенесенные на бумагу, используются в графическом дизайне. Современные компьютерные технологии позволяют не только изучать и повторять существующие образцы плетёных узоров, но и создавать новые в соответствии с заданным стилем.

\section{О программе автоматизированной генерации и редактирования плетёнок MonPlet}

Для создания плетёнок в монгольском стиле разработан редактор и генератор MonPlet [1]. В принятой в программе математической модели две половины орнамента считаются симметричными, несмотря на различия в переплетениях. Чересстрочные переплетения расставляются программой автоматически. В режиме Редактора предоставляется возможность отрисовки узоров как замкнутых, так и разомкнутых, т.е. фактически можно повторить все примеры из литературы, а также создать множество своих вариантов. При этом с помощью четырех осей симметрии можно симметрировать (копировать по правилам осевой симметрии) части узоров, быстро получая различные образцы. При автоматической генерации плетёных 
узоров создаются все математически возможные стилизованные монгольские узоры. Из них для графического дизайна и воспроизведения в материале необходимо выбирать наиболее красивые и оригинальные. В программе имеется возможность изменять художественное оформление плетёнки - расстояние между лентами, ширину и толщину ленты и окантовки, радиус поворота ленты, цвет фона, ленты и окантовки.

\section{Классификация традиционных плетеных орнаментов}

У монголов и бурят - родственных кочевых народов - общий язык, сходные, во многом идентичные обычаи и традиции. Плетение и особые узлы у этих народов употребляются до настоящего времени при изготовлении конской сбруи, плёток, для отделки предметов традиционного костюма, создания наверший для головных уборов, пуговиц. Плетёными орнаментами декорируют двери юрт, мебель, разнообразные бытовые предметы, ювелирные изделия. Самый известный из этих узлов - «вечный узел» («улдзий» по-монгольски или «улзы» по-бурятски), является одним из восьми символов буддизма. Это замкнутая плетёнка из одной ленты, следуя вдоль которой, невозможно найти ни начала, ни конца. Этот знак символизирует вечную жизнь, служит пожеланием бесконечного мира и счастья.

Бурятские и монгольские плетёные узоры во многом схожи, они выполнены в едином стиле, который для краткости назовём монгольским. Характерными чертами этого стиля является квадратная решетка, лежащая в основе построения плетёных узоров, плавные (по дуге окружности) или прямоугольные изгибы лент, и наличие в узоре хотя бы одной из возможных симметрий: зеркальной (m) или поворотной (n).

Передаваемые из поколения в поколение образцы монгольских плетёных розеток (обособленных узоров) опубликованы в книгах Л. Батчулууна [2, с. 255-260] и Ц. Ядамжава [3, с. 52-56], традиционные бурятские плетёнки - в альбоме Л. Доржиева [4, с. 23, 52, 56, 59 и др.]. Всего нами рассматривалось более двухсот образцов народных узоров, из которых были исключены орнаменты, построенные на неравномерной сетке или имеющие другие отклонения от вышеназванных условий. В результате осталось 179 плетёнок, которые были проанализированы более полно.

Нужно отметить, что для рисования плетёных узоров художнику необходимо использовать чертёжные инструменты - линейку, циркуль. Мастер должен быть очень внимательным, чтобы не ошибиться в порядке переплетения лент, в соблюдении размеров и симметрии. Чем больше размер сетки-основы, тем больше вариантов плетёнок можно нарисовать, и тем эта задача сложнее. Наверное, поэтому большинство традиционных узоров вписывается в поля от 6х6 до 8х8 клеток («улзы» строится в поле $5 \times 5$ клеток). Эти орнаменты достаточно просты, но и красивы. В больших полях рисование плетёнок вручную более трудоёмко, поэтому, вероятно, число таких образцов не столь велико (рис. 1а).
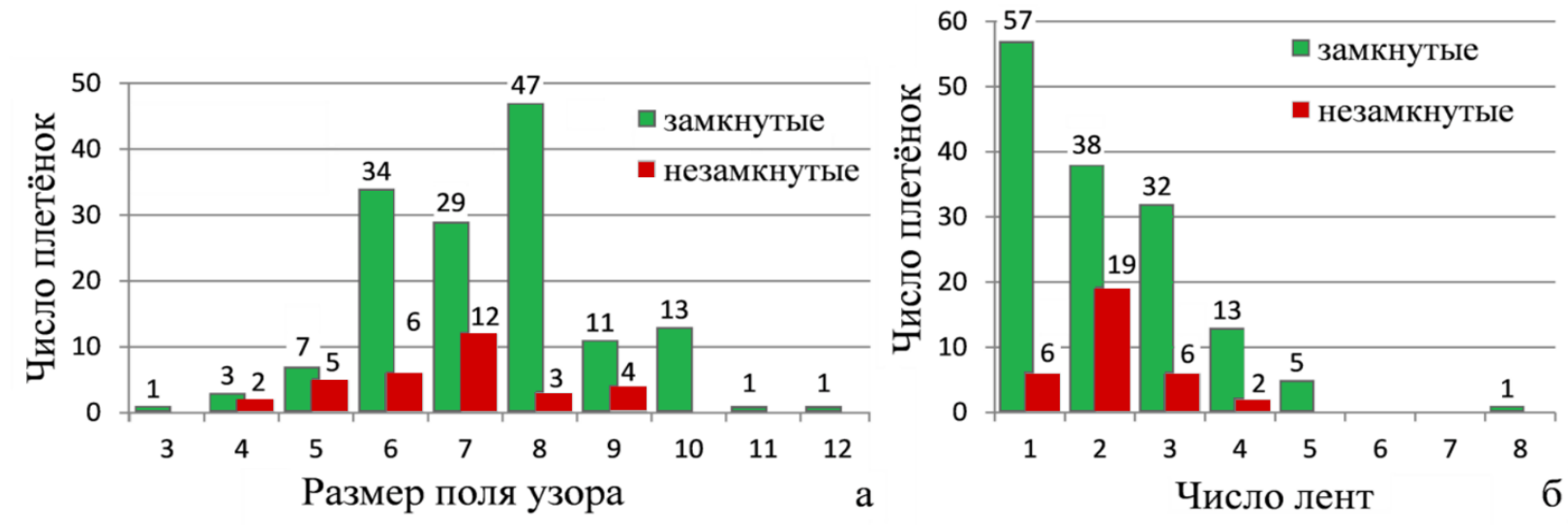

Рис. 1. Распределение 179 образцов плетёнок: a — по размеру поля, б — по числу лент

В процессе оцифровки и систематизации этих орнаментов было установлено, что большинство плетёнок состоит из одной замкнутой ленты, а более восьми лент в образцах не

International Culture \& Technology Studies, Vol. 2, No. 2-3 
встречается (рис. 1б), т.е. с точки зрения математики большинство монгольских плетёных узоров являются узлами.

\section{Элементы теории узлов в приложении к плетёнкам}

Узлы интересуют не только дизайнеров и искусствоведов, но и математиков, и теория узлов пытается объяснять и прогнозировать различные свойства этих математических объектов, необходимых для понимания природы топологии и геометрии в трехмерном пространстве. «Узлом» в математике называют замкнутую кусочно-линейную кривую в трехмерном Евклидовом пространстве R3. Узлы, состоящие из двух и более сплетённых окружностей, называют «зацеплениями». Таким образом, замкнутые плетёные орнаменты в терминах теории узлов представляют собой узлы и зацепления. На рис. 2 показаны примеры монгольских плетёнок из разного числа лент.

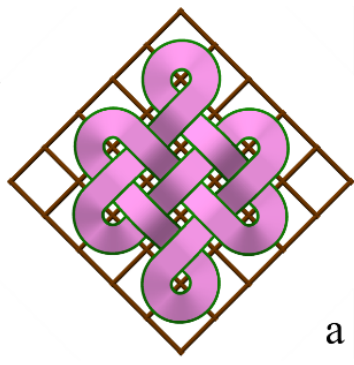

a

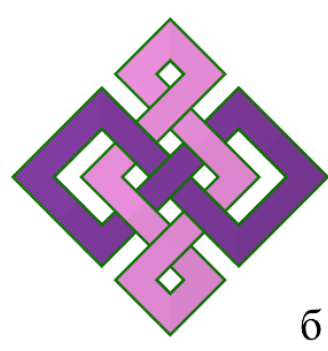

6

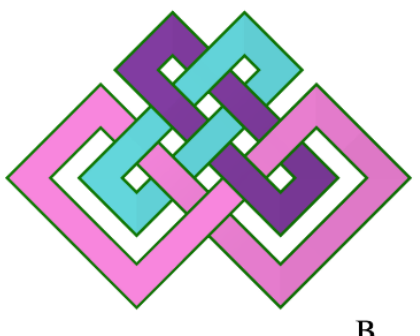

B

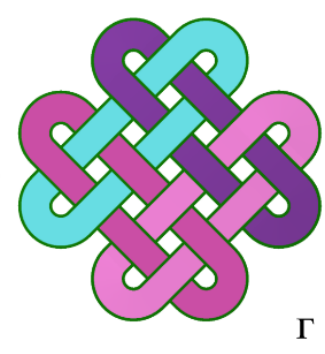

Рис. 2. Примеры монгольских плетёнок: а - «улзы» на сетке $5 \times 5$ клеток, б-г зацепления из двух, трёх и четырёх лент

Узлы в общем представлении - это трёхмерные объекты, а плетёные узоры - условнотрёхмерные, так как переплетения лент занимают небольшой объем, и узор наблюдается с одной, а часто бывает одинаковым с двух сторон. Для сравнения между собой узлов (выявления их эквивалентности) принято рассматривать проекции узлов на плоскость ХОҮ, или их плоские диаграммы. Плоскость выбирают таким образом, чтобы на проекции получалась гладкая кривая с несколькими точками самопересечения, где в каждой точке пересекаются две ветви этой кривой. При этом в каждой точке пересечения одна из ветвей проходит выше (то есть имеет большую координату z), а другая - ниже. Нижняя ветвь на рисунках часто изображается с разрывом, а верхняя - сплошной линией. В плетёных узорах точки пересечения точно зафиксированы сеткой, и ленты пересекаются только под прямыми углами. Если мы будем рассматривать плетёнки как плоские диаграммы, мы сможем лучше изучить их математическую природу.

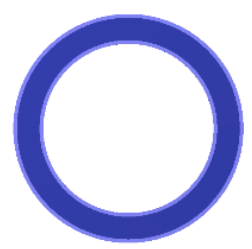

a

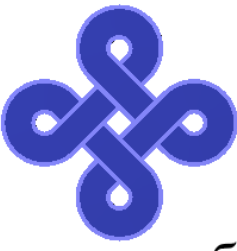

6

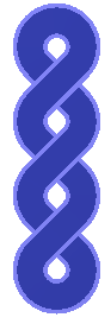

B

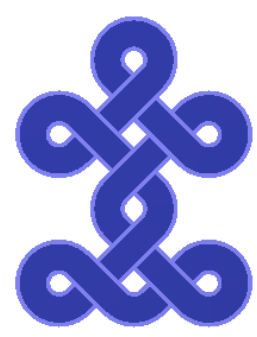

$\Gamma$

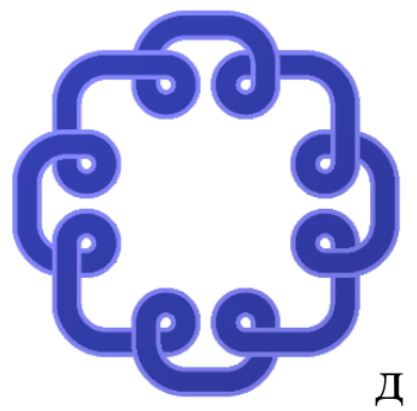

Д

Рис. 3. Примеры монгольских плетёнок в разных полях, изотопных тривиальному узлу: a - тривиальный узел, б - поле $4 \times 4$, в $-5 \times 5$, г - 6x6, д - $10 \times 10$ клеток

Узлы классифицируют по понятию сложности. Простейший (незапутанный) узел, где число пересечений $\mathrm{N}=0$, называют тривиальным (рис. 3a). Среди монгольских плетёнок имеются образцы, казалось бы, с множеством пересечений, которые, однако, изотопны тривиальному узлу, т.е. их можно распутать (Рис. 3, б-д), используя первое движение Рейдемейстера [5, с. 124]. Узлы изотопны, если один из них можно непрерывно продеформировать в другой [5, с. 122]. Вопрос об изотопии двух узлов - главный в теории узлов. Этот вопрос очень сложен, математики не могут решить его уже более полутора веков. Существующий алгоритм невозможно реализовать на 
современных компьютерах, однако частные решения оказались чрезвычайно важны и применимы не только в математике, но и в физике, генетике, гидродинамике и других не чисто математических направлениях исследований.

Число самопересечений $\mathrm{N}$, то есть число двойных точек в плоской диаграмме узла, используют в качестве одной из мер сложности узлов. В обозначениях узлов на первом месте ставится число самопересечений $\mathrm{N}$, на втором - порядковый номер узла. Если не рассматривать зеркальные отражения, то существует всего один тип узла, где $\mathrm{N}=3$, - это так называемый «трилистник», и один тип узла с $\mathrm{N}=4$. При $\mathrm{N}=5$ существует два разных узла, а при $\mathrm{N}=6$ - три. При $\mathrm{N}=7$ разных узлов уже семь, и, начиная с этого момента, число типов узлов начинает резко возрастать. При $\mathrm{N}=13$ их уже 12965 , при $\mathrm{N}=16$ - 1701935 . Не все проекции простых математических узлов обладают симметрией, поэтому число соответствующих им «простых» плетёных узоров будет меньше, чем число узлов, но оно также велико. При этом для узорных плетёнок характерно использование развязываемых петель и различные конфигурации больших петель (>2 клеток), что также увеличивает количество вариаций.

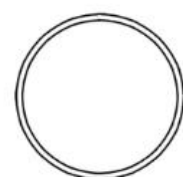

0_1
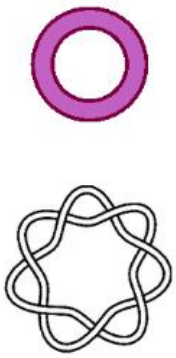

71

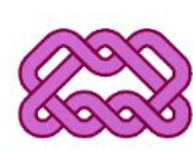

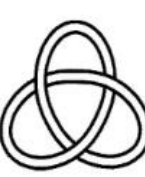

3_1
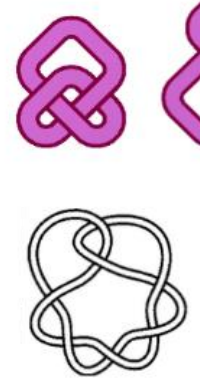

$7 \_2$

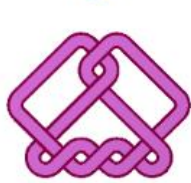

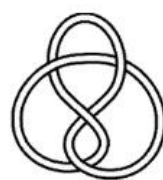

4_1

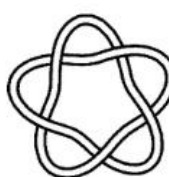

5_1
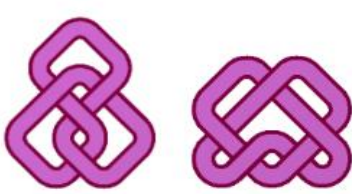

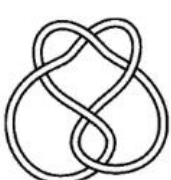

5_2

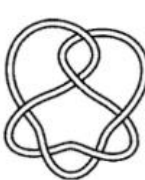

$6 \_1$

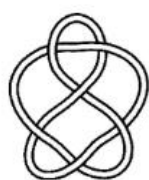

6_2
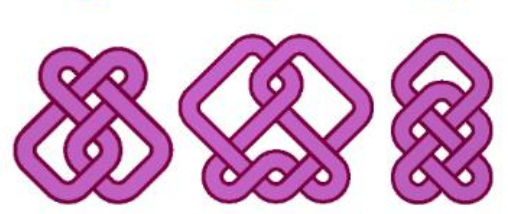

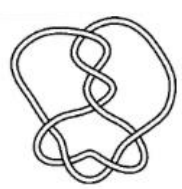

7_3

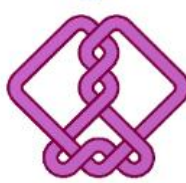

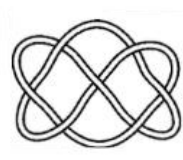

74

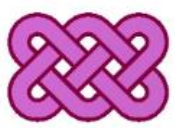

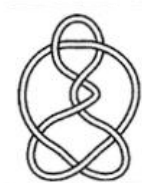

7_5

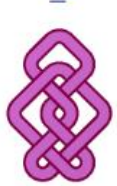

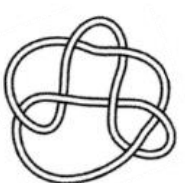

7_6

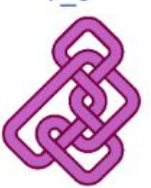

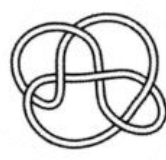

6_3
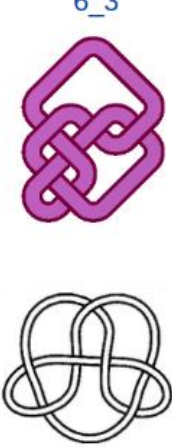

77

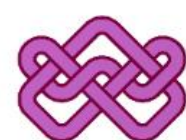

Рис. 4. Примеры узлов $\mathrm{c}$ наименьшим числом двойных самопересечений $\mathrm{N}$ и соответствующих им простых плетёнок, прорисованных в монгольском стиле

На рис. 4 показаны первые 15 узлов из таблицы простых узлов [6] и соответствующие им примеры простых плетёнок в монгольском стиле. «Простые» они потому, что созданы из характерных петель наименьшей возможной величины (с учётом решетки), т.е. имеют минимальную длину ленты. Из рисунка видно, что плетёнки к узлам 6_3 и 7_6 не обладают какойлибо симметрией, а остальные имеют по одной зеркально-поворотной оси симметрии, кроме узла 7_4, который и есть «вечный узел», если добавить две развязываемые петли к средним петлям. Этот узел обладает двойной зеркально-поворотной симметрией. Кроме него среди литературных образцов имеется ещё только одна плетёнка - аналогичная узлу 6_2. Трилистник встречается в монгольских узлах как симметрируемая часть узора или в преобразованном виде как, например, показано в табл. 1, где рассмотрены замкнутые образцы литературных плетёнок (всего их 12), построенные в малых полях - от $3 \times 3$ до $5 \times 5$ клеток, в сравнении с простыми узлами. Развязываемые петли придают узлам своеобразие и эстетическую привлекательность, преобразуя их в плетёный орнамент, но при сравнении плетёнок с простыми узлами этими петлями необходимо пренебрегать. 
Таблица 1. Монгольские образцы узоров в малых полях, в соответствии с простыми узлами и зацеплениями

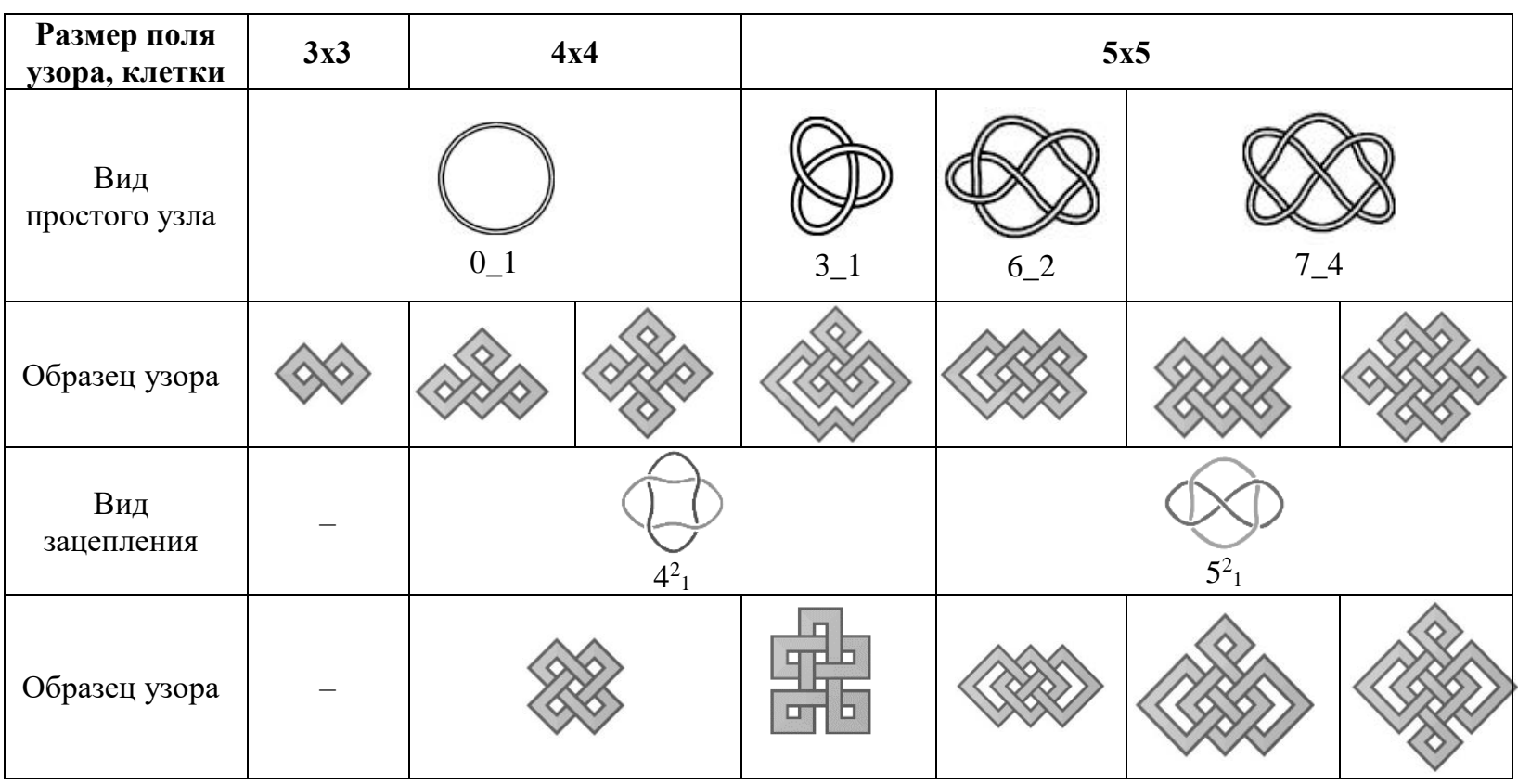

Число двойных точек в образцах плетёнок, заполняющих всё поле, построенных в поле 6х6 клеток, достигает $16,7 \times 7-25,8 \times 8-36,9 \times 9-49,10 \times 10-64$, т.е. числа достаточно большие. При этом в нечетных полях плетёнки чаще образуются из одной ленты, а в четных - из нескольких звеньев. На данный момент таблицы простых узлов построены до 16 пересечений, зацеплений - до $\mathrm{N}=9$. Но здесь необходимо отметить то, что в плетёнках симметрируемые части узора повторяются от двух до четырех раз, т.е. узлы и зацепления могут умножаться (следовать одно за другим), кратно увеличивая число точек пересечений. Например, на рис. 5 показаны примеры плетёнок на основе трилистника (а-г - имеются в образцах, д - создан в программе MonPlet. B примерах рис. 5 (а, в) добавляются петли по первому движению Рейдемейстера, в образцах (б-д) используется умножение (симметрирование) узлов.

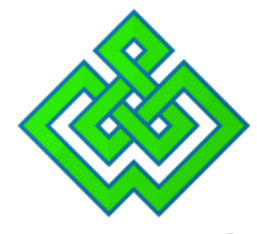

a

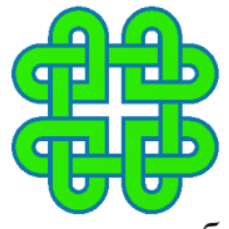

б
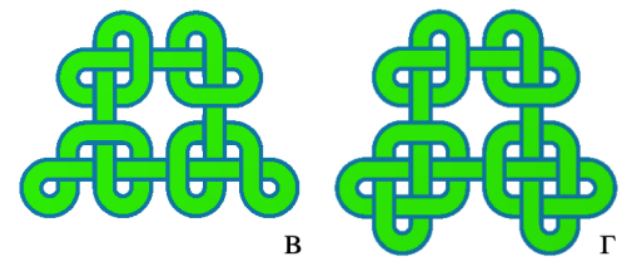

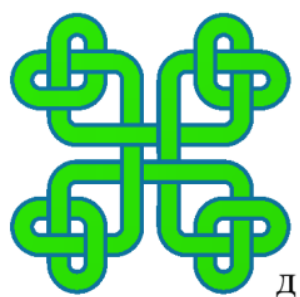

Рис. 5. Примеры плетёнок на основе узла трилистник: a $-3 \_1$ с дополнительной и увеличенной петлями; б, в, д - $4 * 3 \_1$ в различных вариациях; г $-2 * 3 \_1 * 2 * 6 \_2$

\section{Заключение}

Одним из путей оптимизации работы генератора монгольских плетёнок MonPlet может быть применение классификации монгольских плетёных орнаментов (МПО) с помощью элементов теории узлов. Необходимо проанализировать все варианты образцов плетёнок, начиная с малых полей и выделяя те, что представляют собой простые узлы и зацепления, построенные в данном стиле и имеющие наименьшую длину. Составив, таким образом, таблицы простых узлов и зацеплений в стиле МПО и применяя к каждому элементу этих таблиц два простых правила: растяжение отдельных участков для получения стилизованных наружных петель и внутренних пустот и создание дополнительных (развязываемых) пересечений, а также умножение получающихся узлов, можно создать множество вариантов плетёнок в монгольском стиле. Так же могут быть проведены специальные операции - не изменяющие структуру и придающие 
своеобразие. Это может быть искажение сетки и добавление дополнительных декоративных элементов (растительные завитки, геометрические и зооморфные мотивы, шарф-хадак и т.п.).

\title{
Литература
}

[1] Кочева Т.В., Шолохов Е.С. Дизайн монгольского плетёного орнамента // Дизайн. Материалы. Технология. № 4 (19). 2011. С. 71-75.

[2] Батчулуун Л. Монгол эсгий ширмэлийн урлаг. Улаанбаатар, 1999. С. 255-260.

[3] Ядамжав Ц. Орнаменты. Улан-Батор, 2009. С. 52-56.

[4] Бурятский орнамент в творчестве Лубсана Доржиева. М.: МИРТ, 1992. 128 с.

[5] Мантуров В.О. Экскурс в теорию узлов. Соросовский образовательный журнал. Т. 8. № 1. 2004. С. 122127.

[6] The Rolfsen Knot Table. URL: http://katlas.math.toronto.edu/wiki/The Rolfsen_Knot_Table (дата обращения: 11.11.2017).

\section{Application of the knot theory to the Mongolian knot design}

\author{
T.V. Kocheva
}

Institute of physical materials science of Siberian Branch of RAS

\begin{abstract}
Annotation. Many peoples have a tradition of using various knots for economic and other purposes. Since ancient times, beautiful hand-drawn knots are used to decorate many objects, and these days they are widely used by designers. Almost two centuries ago, mathematicians began to study the knots, and since then the knot theory has been successfully developing, finding application in various scientific directions - physics, biology, and art. The article describes an attempt to classify traditional Mongolian interlaced ornaments according to the tables of simple knots with the goal of improving the work of the automated knot editor MonPlet.
\end{abstract}

Keywords: knot, knot theory, interlaced pattern, computer-aided design, MonPlet.

\section{References}

[1] Kocheva T.V., Sholohov E.S. Dizayn mongolskogo pletenogo ornamenta [Design of the Mongolian interlaced ornament]. Design. Materials. Technology. № 4 (19). 2011. Pp. 71-75.

[2] Batchuluun L. Mongol esgiy shirmeliyn urlag [Mongolian felt quilted art]. Ulaanbaatar, 1999. Pp. 255-260.

[3] Yadamzhav Ts. Ornamentyi [Ornaments]. Ulaanbaatar, 2009. Pp. 52-56.

[4] Buryatskiy ornament $\mathrm{v}$ tvorchestve Lubsana Dorzhieva [Buryad pattern in Lubsan Dorziev's works]. M.: MIRT, 1992. 128 p.

[5] Manturov V.O. Ekskurs v teoriyu uzlov. Sorosovskiy obrazovatelnyiy zhurnal [Excursion into the knots theory. Soros Educational Journal]. T. 8. No. 1. 2004. Pp. 122-127.

[6] The Rolfsen Knot Table // URL: http://katlas.math.toronto.edu/wiki/The Rolfsen_Knot_Table (access date: $11 / 11 / 2017)$. 